\title{
Clinical Pharmacy Activities: We Know What to Do, but for Whom Should We Do It?
}

Clinical pharmacy is defined as "a health science discipline in which pharmacists provide patient care that optimizes medication therapy and promotes health, wellness, and disease prevention" and "embraces the philosophy of pharmaceutical care". ${ }^{1}$ The role of the clinical pharmacist is to promote effective, evidence-based, safe, and cost-conscious drug therapy to improve patient outcomes. ${ }^{2-4}$

The World Health Organization and the International Pharmaceutical Federation ${ }^{5}$ have stated that pharmacist services "have been associated with improved health and economic outcomes, a reduction in medicine-related adverse events, improved quality of life, and reduced morbidity and mortality" (p. 12). These positive outcomes have been demonstrated in observational studies, randomized controlled trials, and systematic reviews. ${ }^{6-10}$

Recently, consensus clinical pharmacy key performance indicators (cpKPIs) were developed in Canada. ${ }^{11} \mathrm{~A}$ cpKPI is a quantifiable process measure of a clinical pharmacist activity that has been shown to be associated with positive outcomes. ${ }^{11}$ The $8 \mathrm{cpKPI}$ activities are reconciling admission medications, participating in interprofessional patient care rounds, developing and initiating a pharmaceutical care plan, resolving drug therapy problems (DTPs), educating patients during their hospital stay, educating patients at discharge, reconciling medications at discharge, and providing comprehensive direct patient care in collaboration with the healthcare team. . $^{6-11}$

Given the relatively limited number of inpatient clinical pharmacists in Canada (fewer than 5000 across the country) ${ }^{12}$ it is clear that demand for these cpKPI activities will be greater than the system's capacity to deliver them to all patients. Therefore, some mechanism is needed to prioritize delivery of cpKPI activities to patients. The value index has been proposed to help pharmacists prioritize clinical activities. ${ }^{13}$ The value index takes into account the prevalence of the condition of interest in the patient population, the quality aggregate of the proposed activity (where the quality aggregate encompasses quality of evidence, effectiveness in relation to clinically important outcomes, impact on safety, efficiency, direct link between pharmacist's activity and outcome, and reliance on the pharmacist to perform the activity), and the effort required to perform the activity. ${ }^{13}$

Complex chronic conditions are prevalent and impactful diseases that account for a disproportionate number of emergency department visits, hospital admissions and readmissions, and prolonged lengths of stay, as well as a disproportionate amount of overall health resource utilization in Canada. ${ }^{14,15}$ A very small number of case-mix group diseases account for a significant proportion of acute care bed utilization across Canada. For example, within the Interior Health authority of British Columbia, the leading nonsurgical diseases driving case-mix group data are heart failure, atrial fibrillation, ischemic heart disease, acute coronary syndrome, chronic obstructive pulmonary disease, pneumonia, urinary tract infection, depression, poisoning or toxic drug effect, and acute gastrointestinal bleeding (S. McMillan, Strategic Information Analyst, Strategic Information Management, Interior 


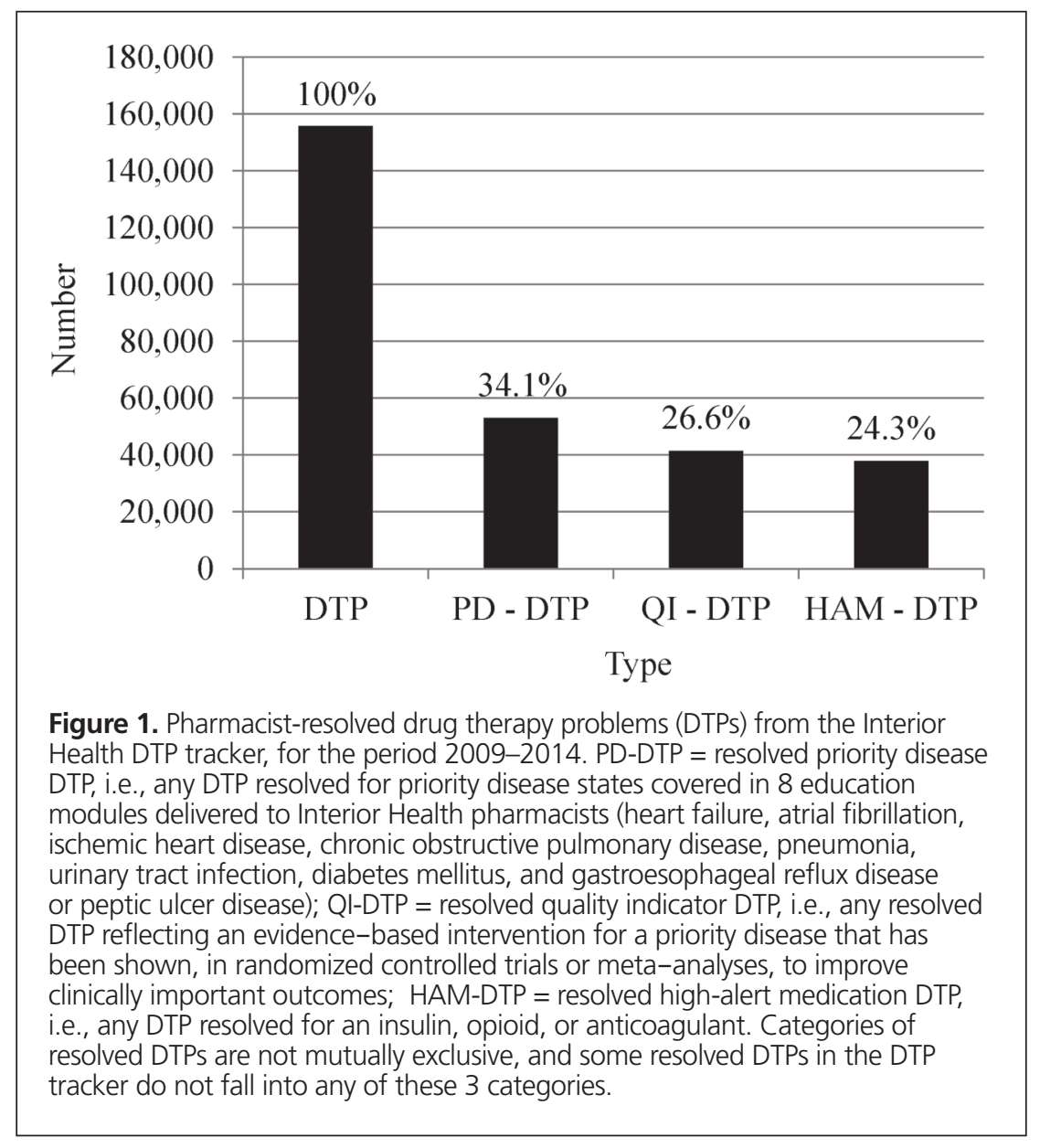

Health: personal communication, February 19, 2015); these are consistent with Canadian case-mix group data. ${ }^{16}$ Prevalent and impactful complex chronic conditions and case-mix group diseases should be considered as "priority diseases".

The US Institute for Safe Medication Practices defines highalert medications as "drugs that bear a heightened risk of causing significant patient harm when used in error". ${ }^{17}$ Complex medication regimens pose risks to patient safety or adherence because of complex dosing schedules, complex methods of administration, and potential for drug interactions. ${ }^{2}$

Pharmacy leaders should assign pharmacists to service areas or wards where there is evidence that their clinical services will improve clinically important patient outcomes. ${ }^{6-10}$ Furthermore, pharmacy leaders and pharmacists should consider prioritizing cpKPI activities to areas with patients who have priority diseases and who are receiving high-alert or complex medication regimens. Ultimately, as shown in the recent literature, providing pharmacists with the opportunity to provide evidence-based activities to patients with priority diseases and receiving high-alert or complex medication regimens should improve the quality of drug therapy, patients' knowledge and adherence to therapies, and health and economic outcomes. ${ }^{18}$

Clinical performance indicator systems are required to monitor and improve the delivery of cpKPI activities and to characterize the
DTPs that are resolved by pharmacists. A DTP tracker that captures disease, drug, and DTP action fields for DTPs resolved by pharmacists shows that Interior Health pharmacists resolved a total of 155701 DTPs between 2009 and 2014 (Figure 1). Queries to the DTP tracker database can be used to characterize different categories of pharmacist-resolved DTPs. For example, a pharmacistresolved DTP for heart failure would be considered a resolved priority disease DTP (PD-DTP), and initiating a ß-blocker for heart failure would be considered a resolved quality indicator DTP (QI-DTP). These data show that Interior Health pharmacists are caring for patients with priority diseases, making evidence-based interventions that are expected to improve health and economic outcomes, and improving the safety of medication use.

The cpKPIs can be used to clearly define expectations of care, improve accountability, and set benchmarks for the effectiveness, productivity, and efficiency of pharmacists. Prioritization of cpKPI activities toward patients with priority diseases who are receiving high-alert or complex medication regimens is important to ensure improvement in patient outcomes and return on the investment in clinical pharmacy services. Future areas of research for pharmacists should include developing evidence-informed, consensus-based QI-DTP interventions for pharmacists in specific therapeutic areas. 
References

1. American College of Clinical Pharmacy. The definition of clinical pharmacy. Pharmacotherapy. 2008;28(6):816-7.

2. CSHP 2015 - targeting excellence in pharmacy practice [website]. Ottawa (ON): Canadian Society of Hospital Pharmacists; 2015 [updated 2015 Nov 9; cited 2015 Nov 9]. Available from: www.cshp.ca/cshp2015/index_e.asp

3. Model standards of practice for Canadian pharmacists. Ottawa (ON): National Association of Pharmacy Regulatory Authorities; 2009 [cited 2015 Nov 9]. Available from: http://napra.ca/Content_Files/Files/Model_Standards_of_ Prac_for_Cdn_Pharm_March09_Final_b.pdf

4. Blueprint for pharmacy: the vision for pharmacy. Ottawa $(\mathrm{ON})$ : Canadian Pharmacists Association; 2008 [cited 2015 Nov 9]. Available from: http://blueprintforpharmacy.ca/docs/pdfs/the-vision-for-pharmacy_ apr-1-09.pdf

5. Wiedenmayer K, Summers RS, Mackie CA, Gous AGS, Everard M. Developing pharmacy practice: a focus on patient care. Handbook - 2006 edition. Geneva (Switzerland); World Health Organization and International Pharmaceutical Federation; 2006.

6. Gillespie U, Alassaad A, Henrohn D, Garmo H, Hammarlund-Udenaes $\mathrm{M}$, Toss $\mathrm{H}$, et al. A comprehensive pharmacist intervention to reduce morbidity in patients 80 years or older: a randomized controlled trial. Arch Intern Med. 2009;169(9):894-900.

7. Makowsky MJ, Koshman SL, Midodzi WK, Tsuyuki RT. Capturing outcomes of clinical activities performed by a rounding pharmacist practicing in a team environment: the COLLABORATE study. Med Care. 2009; 47(6):642-50.

8. Kaboli PJ, Hoth AB, McClimon BJ, Schnipper JL. Clinical pharmacists and inpatient medical care: a systematic review. Arch Intern Med. 2006; 166(9):955-64

9. Bond CA, Raehl CL. Clinical pharmacy services, pharmacy staffing, and hospital mortality rates. Pharmacotherapy. 2007;27(4):481-93.

10. Chisholm-Burns MA, Kim Lee J, Spivey CA, Slack M, Herrier RN, Hall-Lipsy E, et al. US pharmacists' effect as team members on patient care: systematic review and meta-analyses. Med Care. 2010;48(10):923-33.

11. Fernandes O, Gorman SK, Slavik RS, Semchuk WM, Shalansky S, Bussières JF, et al. Development of clinical pharmacy key performance indicators for hospital pharmacists using a modified Delphi approach. Ann Pharmacother. 2015;49(6):656-69.

12. Pharmacists workforce, 2012 - provincial/territorial highlights. Ottawa $(\mathrm{ON})$ : Canadian Institute for Health Information; 2012 [cited 2015 Nov 12]. Available from: https://secure.cihi.ca/free_products/PharmacistWorkforce2012HighlightsEN.pdf
13. Bruchet N, Loewen P, de Lemos J. Improving the quality of clinical pharmacy services: a process to identify and capture high-value "quality actions." Can J Hosp Pharm. 2011;64(1):42-7.

14. 2014/15-2016/17 service plan. Victoria (BC): British Columbia Ministry of Health; 2014. pp. 9, 15.

15. Broemeling A, Watson D, Black C. Chronic conditions and co-morbidity among residents of British Columbia. Vancouver (BC): Centre for Health Services and Policy Research; 2005. p. 26.

16. DAD/HMBD hospitalization rate, average length of stay, top 10 highvolume inpatient hospitalizations and surgeries, and hospital-based newborn rate, 2013-2014 [preformatted table]. Ottawa (ON). Canadian Institute for Health Information; (C) 1996-2015 [cited 2015 Nov 12]. Available from: https://www.cihi.ca/en/quick-stats

17. ISMP high-alert medications. Horsham (PA): Institute of Safe Medication Practices; 2015 [cited 2015 Nov 9]. Available from: https://www.ismp.org/ tools/highalertmedicationLists.asp

18. Anderegg SV, Wilkinson ST, Couldry RJ, Grauer DW, Howser E. Effects of a hospitalwide pharmacy practice model change on readmission and return to emergency department rates. Am J Health Syst Pharm. 2014; 71(17):1469-79.

Richard S Slavik, BSC(Pharm), ACPR, PharmD, FCSHP

Manager - Pharmacy Professional Practice

Pharmacotherapeutic Specialist - Critical Care

Interior Health Pharmacy Services

Kelowna, British Columbia

Marlys LeBras, BSP, ACPR

Postgraduate Doctor of Pharmacy Student

The University of British Columbia

Vancouver, British Columbia

Sean K Gorman, BSC(Pharm), ACPR, PharmD

Pharmacotherapeutic Specialist - Critical Care

Coordinator - Clinical Quality and Research

Interior Health Pharmacy Services

Kelowna, British Columbia

Competing interests: None declared.

\section{CJHP Subscriptions 2016 / Abonnements au JCPH 2016}

In 2015, we moved to an online only version of CJHP and introduced the institutional online subscription option. CJHP online is included as a benefit of CSHP membership. All prices are in Canadian funds.

En 2015, nous avons migré vers la publication d'une seule version du $J C P H$, soit la copie électronique en ligne, et nous avons introduit en option un abonnement institutionnel. L'abonnement à la version électronique du $J C P H$ publiée en ligne est inclus dans les droits d'inscription à la SCPH. Tous les prix sont en dollars canadiens

\begin{tabular}{llll}
$\begin{array}{l}\text { Subscriber group / } \\
\text { Groupe d'abonnés }\end{array}$ & $\begin{array}{l}\text { Individual Online Subscription / } \\
\text { Abonnement individuel en ligne }\end{array}$ & $\begin{array}{l}\text { Institutional Online Subscriptions / } \\
\text { Abonnement institutionnel en ligne }\end{array}$ \\
\hline Nonmembers / & $\$ 160.00$ per year, plus GST or HST & $\$ 480.00$ per year, plus GST or HST \\
Non-membres & $160,00 \$$ par an, plus TPS ou TVH & $480,00 \$$ par an, plus TPS ou TVH
\end{tabular}

If you would like to purchase a subscription, please fill-out our CJHP 2016 Subscription Application Form, which can be found on the CJHP website: www.cjhp-online.ca. Please direct any comments or questions to cjhpedit@cshp.ca.

Si vous désirez vous abonner, veuillez remplir le formulaire d'abonnement au JCPH 2016. Vous pouvez l'obtenir en visitant le site Web du JCPH : www.cjhp-online.ca. Pour tout commentaire ou toute question, veuillez vous adresser à cjhpedit@cshp.ca. 